Assessing Accuracy of Knowledge of Cognitive Effects of Normal Ageing and Mild Stage of Alzheimer's disease

Gemma F Bettens ${ }^{1}$, Tamara Ownsworth ${ }^{1}$, Lydia Hohaus ${ }^{1}$, Yvette McKendry ${ }^{1}$

${ }^{1}$ School of Applied Psychology, Griffith University, Brisbane, Australia

Keywords: Scale Development, Dementia, Ageing, Misconceptions, Cognitive changes

Address for correspondence:

Associate Professor Tamara Ownsworth

School of Applied Psychology

Griffith University

Nathan QLD 4111

Australia

Ph: $\quad+61737353307$

Fax: $\quad+61737353399$

Email: t.ownsworth@griffith.edu.au 


\section{Assessing Accuracy of Knowledge of Cognitive Effects of Normal Ageing and Mild}

\section{Stage of Alzheimer's disease}

\section{Journal of Aging and Mental Health}

Objective: This study aimed to develop and pilot the Alzheimer's Disease and Ageing Perception Scale (ADAPS), examine theory consistent differences and convergent validity, and identify misconceptions of the cognitive effects of ageing and mild AD.

Method: After piloting a large pool of items with a panel of ageing and dementia experts $(n=6)$, an item analysis yielded a 25-item version of the ADAPS $(\alpha=.70)$, comprised of a Normal Ageing subscale $(\alpha=.68)$ and Mild AD subscale $(\alpha=.74)$. Participants from the general community $(n=251)$ and aged care professionals $(n=59)$ completed the ADAPS, Knowledge of Memory Ageing Questionnaire (KMAQ), and the Alzheimer's Disease Knowledge Scale (ADKS).

Results: Compared to matched controls, aged care professionals demonstrated greater accuracy of knowledge on the Mild AD subscale $(p<.05)$, but not the Normal Ageing subscale $(p>.05)$ of the ADAPS. The pattern of significant correlations between the ADAPS, KMAQ and ADKS supported the convergent validity of the ADAPS. The most common misconceptions on the ADAPS indicated a tendency for participants to overgeneralise the cognitive effects of normal ageing.

Conclusion: This preliminary study introduces a new tool for assessing accuracy of knowledge of cognitive effects associated with normal ageing and mild AD, and may assist in identifying misconceptions of the ageing process.

Keywords: Scale Development, Dementia, Ageing, Misconceptions, Cognitive changes 


\section{Assessing Accuracy of Knowledge of Cognitive Effects of Normal Ageing and Mild}

\section{Stage of Alzheimer's disease}

Demographic trends indicate a continual increase in the proportion of people in the older age bracket (i.e., > 70 years; Bishop, Lu, \& Yanker, 2010). It is expected that by 2050 approximately 1.5 billion people or $16 \%$ of the world's population will be aged 65 or older (World Health Organisation [WHO], 2011). Alzheimer's disease (AD) is the most common form of dementia and is most typically diagnosed in people over 65 years of age (Murray \& Boyd, 2009). By 2050 it is estimated that AD will affect 1 in 85 people globally (Brookmeyer, Johnson, Ziegler-Graham, \& Arrigh, 2007). Due to the many social implications of an ageing population, these demographic changes need to be accompanied by increased recognition and understanding of the ageing process.

Research indicates that the general public holds various misconceptions about normal ageing and AD (Rust \& See, 2007; Unwin, Unwin, Olsen, \& Wilson, 2008). Common stereotypes associate older age with disease, dependence, and incompetence (Rust \& Kwong See, 2010). Social Cognitive Theory (Bandura, 2001) suggests that people acquire knowledge and behaviour through observation and vicarious experiences, and that considerable social learning occurs either intentionally or unintentionally through models in one's immediate environment. Based on this theory, greater exposure to older adults and people with AD would be expected to increase knowledge and reduce misconceptions concerning the ageing process and $\mathrm{AD}$. Accordingly, research suggests that more frequent interaction with older adults enhances knowledge of the ageing process, which in turn promotes more positive attitudes and behaviour (Davis \& Friedrich, 2004; Galinsky \& Moskowitz, 2000; Hess, 2006; Kemper, 1994). Accuracy of knowledge regarding AD has been found to be relatively poor in the general community, and is lower for people with no experience of AD in their family or 
formal training in the dementia field (Carpenter, Zoller, Balsis, Otilingam \& Gatz, 2011). Due to the gradual onset of $\mathrm{AD}$, early symptoms can be overlooked by patients, family members and physicians alike, often being dismissed as characteristics of normal ageing (Gallagher \& Koh, 2011).

To date, most scales assessing knowledge of AD have focused broadly on prevalence, aetiology, diagnosis, course, symptoms, treatment, risk factors and caregiving (see Carpenter, Balsis, Otilingham, Hanson \& Gatz, 2009). Although breadth of topics is important, few items cover the cognitive effects of the mild stage of $\mathrm{AD}$ in the context of normal age-related change. The Knowledge of Memory Ageing Questionnaire (KMAQ; Cherry et al., 2000) assesses perceptions of both normal age-related and pathological memory changes (e.g., knowledge of mnemonics and memory strategies, mental and physical health conditions affecting memory). Although the KMAQ provides an in-depth assessment of age-related memory processes, changes associated with normal ageing and mild $\mathrm{AD}$ extend beyond memory, and thus a measure that broadly assesses accuracy of knowledge across multiple domains of cognitive function would help to advance research in the field.

Accordingly, the first aim of this study was to develop a new tool, the Alzheimer's Disease and Ageing Perception Scale (ADAPS), and conduct piloting and item analysis for further research use. Secondly, the study aimed to investigate the validity of the ADAPS through examination of theory consistent differences and convergent validity. It was hypothesised that professionals working in aged care would display greater accuracy of knowledge of cognitive effects of mild $\mathrm{AD}$ and normal ageing compared to a general community sample. It was also hypothesised that performance on the ADAPS would be significantly correlated with performance on existing measures assessing knowledge of 
ageing and $\mathrm{AD}$. A third exploratory aim was to examine the nature of misconceptions regarding cognitive effects of normal ageing and mild AD.

\section{Method}

\section{Participants}

General Community Sample. A convenience sample of 251 participants was recruited from the general community through the researchers' own social networks. Participants were eligible if they were aged $<70$ years and spoke English fluently. Participants' age ranged from 18 to 69 years $(M=35.20, S D=13.47)$, with females accounting for $70.8 \%$ of the sample. Education ranged from 7 to 18 years $(M=14.43, S D=2.58)$. As shown in Table 1 , most participants previously had some contact with a person with $\mathrm{AD}$ as a family member or friend/acquaintance (45.4\%) or contact with more than one person with $\mathrm{AD}$ through both a family member and a friend/acquaintance with $\mathrm{AD}(30.3 \%)$.

Aged Care Professionals. A sample of 59 aged care professionals was recruited to participate from aged care facilities in Brisbane, Australia. Professionals were eligible for the study if they met the following criteria: aged $<70$ years, have worked in an aged care setting for at least five years and fluent in English. Participants in the professional sample were aged 23 to 65 years $(M=50.95, S D=10.15)$, and females accounted for $91 \%$ of the sample. Education ranged from 11 to 18 years $(M=15.80, S D=1.74)$. Table 1 summarises the occupational roles of the aged care professionals.

Insert Table 1 about here

\section{Measures}

Alzheimer's Disease and Ageing Perception Scale (ADAPS). The four main stages for developing the ADAPS entailed: 1) item generation, 2) piloting, 3) item analysis, and 4) 
validation. Items were generated through a review of the ageing and $\mathrm{AD}$ literature and previously validated scales regarding normal ageing and AD (see review Carpenter et al., 2009). Two clinical neuropsychologists and a developmental psychologist contributed feedback on the initial set of items. A multiple choice format was selected because the ADAPS was designed to measure accuracy of knowledge, which involves evaluating responses as either correct or incorrect as opposed to attitudes which are commonly measured by strength of agreement (Shum, O'Gorman, \& Myors, 2006). Sixty items were grouped into three preliminary subscales which comprised of 20 items each, as follows: $\mathrm{A}=$ "Can be characteristic of normal ageing"; B = "Can be characteristic of MILD Alzheimer's disease"; and $\mathrm{C}=$ "Not characteristic of either MILD Alzheimer's disease or normal ageing". In relation to the latter subscale, items were designed to reflect preserved areas of cognitive functioning or unlikely cognitive changes in the context of normal ageing and mild AD; for example "Difficulty contributing to conversation about general subjects e.g. the weather" and "Difficulty pronouncing well known words".

An independent panel of ageing and dementia experts ( $n=6 ; 2$ males, 4 females) with specialised qualifications and proficiency spanning medicine, psychiatry, neuropsychology and nursing were asked to participate in piloting the ADAPS and appraise a preliminary draft. Panel members' average length of experience in the field was 20 years, with all experts having worked at least 10 years in their respective field. Additionally, an older adult (female, aged 77 years) was asked for her input on the wording of items and examples provided, based on her lived experience of ageing. A consensus level of at least $67 \%$ (i.e. four of the six experts agree on the classification) was identified for item retention. Most items that did not meet consensus were from subscales $\mathrm{A}$ and $\mathrm{C}$, and were excluded from the measure. However, qualitative feedback from experts guided the process of rewording items when the 
consensus rule was nearly met (e.g., three of the six experts agreed) in order to retain a larger set of items for the item analysis. A revised set of 40 items (i.e., 10 items on subscale A; 20 items on subscale B; and 10 items on subscale C) was included in the item analysis.

Knowledge of Memory Ageing Questionnaire (KMAQ). The KMAQ (Cherry et al., 2000) was developed to assess the general public's knowledge of normal and pathological memory changes in ageing. The true/false measure consists of 28-items, 19 questions relating to normal age-related memory changes and nine questions concerning pathological memory ageing. Total scores range from 0-28 with higher scores indicating greater knowledge of differences between normal and pathological memory changes. Research on the psychometric properties of the KMAQ provides evidence of convergent and discriminant validity (Cherry et al., 2000) and content validity (Jackson, Cherry, Smitherman, \& Hawley, 2008). The KMAQ has demonstrated low internal consistency $(\alpha=.55)$, which Cherry et al. (2000) argued may be due to the breadth of topics assessed for both normal and pathological memory ageing. The KMAQ has been used to compare knowledge of normal and pathological memory changes between various samples including police officers (Hawley et al., 2005), students (Cherry et al., 2009; Cherry et al., 2010; Jackson et al., 2008), caregivers, senior service providers (Cherry et al., 2009) and mental health professionals (Cherry et al., 2010; Jackson et al., 2008).

Alzheimer's Disease Knowledge Scale (ADKS). The ADKS (Carpenter et al., 2009) is an updated version of the Alzheimer's Disease Knowledge Test (ADKT; Dieckmann, Zarit, Zarit, \& Gatz, 1988) that reflects a more contemporary understanding of AD. This standardised true/false measure comprises 30 items relating to 7 content domains of AD, including: 1) Assessment and diagnosis; 2) Symptoms; 3) Course; 4) Life impact; 5) Caregiving; 6) Risk factors; and 7) Treatment and management. Total scores range from 0-30 
with higher scores reflecting more accurate knowledge of $\mathrm{AD}$ assessment, symptoms, course, risk factors, treatment, caregiving and life impact. The ADKS demonstrates adequate reliability (test-retest $[\rho \mathrm{I}=.81]$, internal consistency $[\alpha=.71]$ ) and content, concurrent and discriminant validity (Carpenter et al., 2009). Factor analysis supported the use of a total score on the ADKS to reflect overall knowledge of AD. The ADKS has been employed by other researchers to examine accuracy of knowledge of AD (Hudson, Pollux, Mistry, \& Hobson, 2012; Nordhus, Sivertsen, \& Pallesen, 2012).

\section{Procedure}

The ADAPS, ADKS and KMAQ were converted to an online format through Lime Survey V1.9. Randomisation of scale order was implemented to minimise order effects in completing the three scales. Following university ethical clearance, surveys were distributed to participants in the general community in hardcopy form and online via the Lime Survey link. In addition to the three scales, participants from the general community completed a brief demographic survey. Aged care professionals were recruited using the following three approaches: 1) an email with a survey link was distributed to all Directors of Nursing (DON) in Queensland via the Nurses in Management Aged Care (NIMAC) email database (i.e., approximately 120 aged care facilities). DONs were invited to forward the email to staff members for them to volunteer in the study; 2) Hard copy versions of the survey were distributed to some aged care facilities by request of the DON at the facility (approximately 40 copies); and 3) participants were recruited at the annual NIMAC conference where a brief presentation about the study was provided and hardcopy versions (approximately 120 copies) of the survey were distributed.

\section{Results}

\section{Preliminary Validation of the ADAPS}


An item analysis was conducted on the 40 items identified through the piloting stage of the ADAPS. Guided by the recommendations of Gregory (2004) and previous approach of Carpenter et al. (2009), the item analysis entailed calculating item discrimination and item difficulty indices, and examining internal consistency. An independent sample of 50 participants was randomly selected from the general community sample $(n=251)$ for this purpose. There were no missing data for this sample. The sample comprised 36 females and 14 males aged 20 - 65 years $(M=31.54 ; S D=10.71)$. No participants from the aged care professional sample were included in this analysis. The Statistical Package for Social Sciences (SPSS) Version 20 was employed for all analyses.

Discrimination Index. This analysis sought to identify items that were least effective at discriminating between high and low overall scorers on the 40-item ADAPS. High scorers (upper quartile, $n=13$ ) and low scorers (lower quartile, $n=13$ ) were identified. High scorers answered 25 - 31 items correctly $(M=27.31, S D=1.84)$ and low scorers answered $14-19$ items correctly $(M=17.00 ; S D=1.58)$. The percentage of participants in each group (i.e., high and low scorers) with correct responses was then calculated for each individual item (Carpenter et al., 2009). The low scorers' percentage was subtracted from the high scorers' percentage to calculate a discrimination index for each item. For example, $23.1 \%$ of the high scorers and $7.7 \%$ of the low scorers answered item 40 correctly. The difference was small (15.4\%), which suggests that most people answered item 40 incorrectly, regardless of their overall knowledge of mild AD and normal ageing. A positive difference of $\geq 20 \%$ was used to indicate adequate item discrimination. A total of 28 items on the ADAPS demonstrated a positive difference of this magnitude (see Table 2). Of the 12 items identified as problematic, two yielded negative item discrimination indices and four items exhibited null differences (i.e., $0.0 \%$ ) between the higher scorers and low scorers. The remaining six items with low 
discrimination indices $(<20 \%)$ were retained provisionally for the item difficulty index and internal consistency analysis.

Item Difficulty Index. The difficulty index represents the percentage of people who answered the item correctly. Items answered correctly or incorrectly by a high percentage of people are unlikely to discriminate among test takers and are therefore candidates for deletion (Carpenter et al., 2009; Gregory, 2004). A difficulty index of .95 indicates that most people answered the item correctly (i.e., $95 \%$ of the sample), and thus the item provides little useful information (Carpenter et al., 2009). In the present analysis, all ADAPS items had a difficulty index between .05 and .95 .

Homogeneity of Items. The ADAPS was designed to reflect a homogeneous scale with items measuring accuracy of knowledge relating to the cognitive effects of normal ageing and mild AD. All items, including those deemed problematic from the item discrimination analysis, were further examined using Cronbach's alpha. Items were excluded if there was a negative correlation with the overall scale score and alpha improved with removal. Eight items were removed through this method, yielding satisfactory internal consistency $(\alpha=.71)$. However, only one item (item 6) remained on subscale ' $\mathrm{C}$ ', and consequently this item was removed. As presented in Table 2 , this process resulted in a 25 item total scale $(\alpha=.70)$, and 7 item Normal Ageing subscale $(\alpha=.68)$ and 18 item Mild AD subscale $(\alpha=.74)$. Overall, internal consistency of the ADAPS was deemed acceptable for research use (DeVellis, 2011).

Insert Table 2 about here

\section{Investigating Accuracy of Knowledge of Normal Ageing and Mild AD}

Data Analysis. Data screening procedures were conducted using SPSS Version 20 according to recommendations by Tabachnick and Fidell (2007). Eight participants (general community sample $n=5$; aged care professionals $n=3$ ) were excluded from all analyses due 
to excessive missing data (i.e., an entire page) on the scales. This resulted in a sample of 196 participants from the general community that was independent from the item analysis sample, and a sample of 56 aged care professionals. The assumptions for relevant parametric ( $t$-tests and Pearson product moment correlations) and non-parametric tests (chi-square) were met.

Preliminary analysis of demographic characteristics for the general community sample ( $n=196)$ identified that level of education was significantly positively correlated with accuracy of knowledge on the ADAPS $(r=.15, p<.05)$. There was no significant correlation between age and accuracy of knowledge $(r=.07, p>.05)$ or significant gender difference $(t=$ $-1.22, p>.05)$. Results of a one-way ANOVA identified that previous contact with a person with $\mathrm{AD}$ was significantly associated with accuracy of knowledge, $F(2,193) 3.16, p<.05$. Independent $t$-tests identified that individuals with no previous contact scored significantly lower on the ADAPS $(M=13.51, S D=3.91)$ than individuals who had contact through both a family member and friend/acquaintance with $\mathrm{AD}(M=15.39, S D=4.14 ; t=-2.37, p<.05, d$ $=.47)$.

Theory Consistent Differences on the ADAPS. Aged care professionals were matched with participants from the general community sample $(n=56)$ on age $(M=50.95, S D=$ $10.15 ; M=47.20, S D=11.19, p>.05$, respectively $)$, gender $(51=$ female; $48=$ female, $p>.05$, respectively) and years of education $(M=15.80, S D=1.74 ; M=15.43, S D=2.33, p>.05$, respectively). The results of three independent $t$-tests conducted on the total ADAPS, Normal Ageing subscale, and Mild AD subscale revealed a significant group difference on the Mild AD subscale. Specifically, aged care professionals displayed greater accuracy of knowledge of cognitive effects of Mild AD $(M=12.34, S D=3.15)$ compared to the general community sample $(M=11.05, S D=3.49 ; t[110]=2.05, p<.05, d=.39)$. There were no significant differences in total ADAPS scores between the professional sample $(M=16.05, S D=3.33)$ 
and general community sample $(M=15.30, S D=3.62 ; t[110]=1.14, p>.05, d=.22)$.

Similarly, scores on the ADAPS Normal Ageing subscale did not significantly differ between the professional sample $(M=3.71, S D=2.45)$ and general community sample $(M=4.25, S D$ $=1.87 ; t[110]=-1.30, p>.05, d=.25)$.

Convergent Validity of the ADAPS. Pearson product moment correlations were conducted between the ADAPS total and subscale scores, and total scores on the ADKS and KMAQ for the general community sample $(n=196)$. As presented in Table 3 , significant positive correlations were found between the ADAPS total score and KMAQ $(p<.05)$ and the ADKS $(p<.01)$. The ADAPS Normal Ageing subscale was significantly correlated with the KMAQ $(p<.01)$ and ADKS $(p<.05)$. The Mild AD subscale of the ADAPS was significantly correlated with the ADKS $(p<.05)$ but not the KMAQ $(p>.05)$. A significant correlation was also found between the ADKS and KMAQ $(p<.001)$.

Insert Table 3 about here

Accuracy of Knowledge and Frequency of Misconceptions. A chi-square test of independence with Yates Continuity Correction identified that accuracy of knowledge on the ADAPS did not significantly differ between the Normal Ageing subscale and Mild AD subscale $(p=.541, p h i=.01)$ for the general community sample. Specifically, the mean proportion of accurate response on the Normal Ageing subscale (56.9\%) was comparable to accuracy on the Mild AD subscale (57.9\%). The same comparison for the professional sample identified a significant difference in the mean proportion of accurate responses across the two subscales $(p<.001, p h i=.30)$. Professionals were significantly more likely to correctly endorse items on the Mild AD subscale (73.5\%) than the Normal Ageing subscale (42.1\%). A further exploratory component involved identifying the 10 items on the ADAPS that were most frequently incorrectly endorsed, thus reflecting common misconceptions for 
normal ageing and mild AD. As shown in Table 4, accuracy rates ranged from $34.7 \%$ to $54.1 \%$ for these 10 items in the general community sample. The five most common misconceptions indicated a tendency for the cognitive effects of mild AD to be misattributed to normal ageing.

Insert Table 4 about here

\section{Discussion}

The broad objective of this study was to develop and validate a new tool to assess accuracy of knowledge of cognitive effects of normal ageing and mild AD. An item analysis yielded a 25-item version of the ADAPS that comprised two subscales (Normal Ageing and Mild AD). There was preliminary support for the validity of the ADAPS from the finding that professionals displayed more accurate knowledge of the cognitive effects of Mild AD than the general community sample. There was evidence of convergent validity for the ADAPS, based on the pattern of significant associations with the ADKS and the KMAQ.

The piloting and item analysis lead to identification of items that were not reliable in distinguishing knowledge of the cognitive effects of normal ageing and mild AD. Some ambiguous wording in the initial version of the ADAPS may have contributed to the lack of consensus between experts, and their feedback improved the clarity of instructions and item wording. The item analysis identified that item discrimination and/or homogeneity was problematic for 15 items, including most items on subscale C. Participants' responses indicated that they mainly endorsed subscale A or B, suggesting that even high scorers on the ADAPS tended to overgeneralise the effects of ageing and mild AD. Items on column $\mathrm{C}$ did not reliably discriminate between levels of knowledge in the present sample, and thus were removed. 
Theory consistent differences were evident for the Mild AD subscale of the ADAPS, indicating that aged care professionals were more accurate at identifying cognitive effects of Mild AD than the general community sample. However, aged care professionals were not more accurate overall in distinguishing the cognitive effects of mild AD from normal ageing than the general community sample. In fact, the proportion of correctly endorsed items on the Normal Ageing subscale was somewhat lower for aged care professionals $(42.1 \%)$ than the general community sample (56.9\%). A possible explanation for this finding is that professionals working in aged care facilities interact most frequently with residents over 75 who have experienced functional decline that warrants nursing care. Rust and See (2007) noted that aged care professionals are likely to gain certain knowledge from their direct work with older adults, but they may also experience gaps in their knowledge. Specifically, it is possible that working with older adults in aged care provides a pathological model of the ageing process. Cherry et al. (2009) also found that knowledge of normal memory ageing was comparable between university students, caregivers and aged care service providers. In future research it would be valuable to include more diverse professional subgroups, including those working in healthy ageing and lifestyle promotion.

Overall, the pattern of significant correlations between the ADAPS, ADKS and KMAQ provided support for the convergent validity of the ADAPS. However, the modest strength of these associations may be due to differences in the underlying constructs assessed.

Specifically, items of the ADAPS were designed to tap the effects of normal ageing and mild $\mathrm{AD}$ across different cognitive domains, as opposed to knowledge of normal and pathological memory ageing (KMAQ) and knowledge of $\mathrm{AD}$ prevalence, aetiology, risk factors, diagnosis, course, symptoms, treatment and caregiving (ADKS). Consistent with the findings of Carpenter et al. (2011), level of education and previous contact with both a family member 
and friend/acquaintance with $\mathrm{AD}$ was related to greater total ADAPS scores, thus highlighting the influence of socio-cultural factors on knowledge of the ageing process.

An exploratory analysis of common misconceptions on the ADAPS revealed a tendency for participants in this study to misattribute cognitive difficulties that occur in mild AD to normal ageing. Cherry et al. (2009) and Jackson et al. (2008) similarly found that an ageist attitude towards adult cognition was common amongst university students and community members. The present study extends upon these findings by identifying everyday situations where misconceptions exist about older adults, and reflect an underestimation of their abilities (e.g., managing finances, completing multi-step activities without assistance,). It is important to acknowledge that the Normal Ageing subscale of the ADAPS only contained seven items, and therefore further research is needed to increase the number of items that reliably assess accuracy of knowledge of the cognitive effects of normal ageing. Notwithstanding this point, the potential implications of these findings are that members of the community, including older adults themselves, may overestimate the cognitive changes associated with normal ageing. Inaccurate knowledge of normal age-related cognitive changes may in turn reinforce ageist stereotypes and contribute to behaviour that undermines the self-efficacy of older adults regarding their independence in the home and community.

A number of limitations need to be acknowledged in this preliminary study. Firstly, participants from the general community were recruited through convenience sampling and were highly educated (i.e., mean years of education $=14.5$ years). Use of population-based sampling in future research would improve the representativeness of the sample and generalisability of the findings. Secondly, the aged care professional sample was relatively small and heterogeneous in occupational characteristics, which may have influenced the findings. Thirdly, a larger number of items on the Normal Ageing subscale would improve 
the reliability and construct validity of the ADAPS. In future research, test-retest reliability and more advanced methods of item analysis, such as differential item functioning (see Strobl, Kopf, \& Zeileis, 2010) are recommended.

Overall, this study employed a systematic approach to developing a new tool that included piloting items with a panel of experts and conducting an item analysis to refine the ADAPS prior to research use. The findings provide preliminary support for the utility of the ADAPS to assess accuracy of knowledge of the cognitive effects of normal ageing and mild AD. Further research is needed to examine the tool's psychometric properties, including responsiveness in the context of educational interventions, as demonstrated for the KMAQ (see Jackson et al., 2008). With further validation the ADAPS may assist to identify misconceptions about the ageing process and guide educational programs for students, professionals and other community groups. Greater knowledge of the early cognitive effects of AD may translate to improved screening and access to intervention to maintain individuals' functioning and quality of life (Epstein \& Hundert, 2002; Jackson et al., 2008). Acknowledgments The authors would like to acknowledge the panel of experts, the NIMAC organisations that assisted with disseminating the survey and the participants. 


\section{References}

Bandura, A. (2001). Social cognitive theory of mass communication. Media Psychology, 3(3), 265-299. Doi: 10.1207/S1532785XMEP0303_03

Bishop, N. A., Lu, T., \& Yankner, B. A. (2010). Neural mechanisms of ageing and cognitive decline. Nature, 464(7288), 529-535. Doi:10.1038/nature08983

Brookmeyer, R., Johnson, E., Ziegler-Graham, K., \& Arrighi, H. M. (2007). Forecasting the global burden of Alzheimer's disease. Alzheimer's and Dementia, 3(3), 186-191. Doi: 10.1016/j.jalz.2007.04.381

Carpenter, B. D., Balsis, S., Otilingam, P. G., Hanson, P. K., \& Gatz, M. (2009). The Alzheimer's disease knowledge scale: Development and psychometric properties. The Gerontologist, 49, 236-247. Doi: 10.1093/geront/gnp023

Carpenter, B. D., Zoller, S. M., Balsis, S., Otilingam, P. G., \& Gatz, M. (2011). Demographic and Contextual Factors Related to Knowledge About Alzheimer's Disease. American Journal of Alzheimer's Disease and Other Dementias, 26, 121-126. Doi:

$10.1177 / 1533317510394157$

Cherry, K. E., Allen, P. D., Boudreaux, E. O., Robichaux, M. L., \& Hawley, K. S. (2009). Knowledge of Memory Aging in Students, Caregivers, and Senior Service Providers. Educational Gerontology, 35(6), 541-552. Doi: 10.1080/03601270902821343

Cherry, K. E., Allen, P. D., Jackson, E. M., Hawley, K. S., \& Brigman, S. (2010). Knowledge of normal and pathological memory aging in college students, social workers, and health care professionals. Educational Gerontology, 36(4), 281-297. Doi: $10.1080 / 03601270903323950$ 
Cherry, K. E., West, R. L., Reese, C. M., Santa Maria, M. P., \& Yassuda, M. (2000). The knowledge of memory aging questionnaire. Educational Gerontology, 26(3), 195-219.

Doi: $10.1080 / 03601270590522161$

Davis, N. C., \& Friedrich, D. (2004). Knowledge of aging and life satisfaction among older adults. The International Journal of Aging and Human Development, 59(1), 43-61. Doi: 10.2190/U9WD-M79K-9HB8-G9JY

DeVellis, R. F. (2011). Scale development: Theory and applications (Vol. 26). Sage Publications, Incorporated.

Dieckmann, L., Zarit, S. H., Zarit, J. M., \& Gatz, M. (1988). The Alzheimer's disease knowledge test. The Gerontologist, 28(3), 402-408. Doi: 10.1093/geront/28.3.402 Epstein, R. M., \& Hundert, E. M. (2002). Defining and assessing professional competence. JAMA: The Journal of the American Medical Association, 287(2), 226-235. Doi: 10.1001/jama.287.2.226

Galinsky, A. D., \& Moskowitz, G. B. (2000). Perspective-taking: Decreasing stereotype expression, stereotype accessibility, and in-group favoritism. Journal of Personality and Social Psychology, 78(4), 708. Doi: 10.1037/0022-3514.78.4.708

Gallagher, M., \& Koh, M. T. (2011). Episodic memory on the path to Alzheimer's disease. Current Opinion in Neurobiology, 21, 929-934. Doi:http://dx.doi.org/10.1016/j.conb. 2011.10.021

Gregory, R. J. (2004). Psychological testing: History, principles, and applications. Boston, MA: Allyn \& Bacon.

Hawley, K. S., Garrity, A. W., \& Cherry, K. E. (2005). Knowledge of normal versus pathological memory aging among police officers. Educational Gerontology, $\quad 31(1)$, 1-17. Doi: $10.1080 / 03601270590522161$ 
Hess, T. M., (2006). Attitudes toward aging and their effects on behavior. In J. E. Birren \& K. W. Schaie (Eds.), Handbook of the Psychology of Aging (6 $6^{\text {th }}$ Ed) (pp. 379-406).

Retrieved from http://books.google.com.au/books?hl=en\&lr=\&id=ILWKTh901Ug C\&oi $=$ fnd \&pg $=$ PA379\&dq $=$ Hess,+ T. + M. $+\% 282006 \% 29 .+$ Attitudes + toward + aging +nd+their+effects+on+behavior.+Handbook+of +the \%09psychology+of +aging, $+6,+379-406 .+\&$ ots $=$ HN6oZ6Dn3m\&sig=vaxq9eqWBSyAqbMQemHObe6GShg\#v= onepa ge\&q\&f=false

Hudson, J. M., Pollux, P. M. J., Mistry, B., \& Hobson, S. (2012). Beliefs about Alzheimer's disease in Britain. Aging \& Mental Health, 16(7), 828-835. Doi:

$10.1080 / 13607863.2012 .660620$

Jackson, E. M., Cherry, K. E., Smitherman, E. A., \& Hawley, K. S. (2008). Knowledge of memory aging and Alzheimer's disease in college students and mental health professionals. Aging and Mental Health, 12(2), 258-266. Doi:

$10.1080 / 13607860801951861$

Kemper, S. (1994). Elderspeak: Speech accommodations to older adults. Aging and Cognition, 1(1), 17-28. Doi: 10.1080/09289919408251447

Murray, L. M., \& Boyd, S. (2009). Protecting personhood and achieving quality of life for older adults with dementia in the US health care system. Journal of Aging and Health, 21(2), 350-373. Doi: 10.1177/0898264308329017

Nordhus, I. H., Sivertsen, B., \& Pallesen, S. (2012). Knowledge about Alzheimer's disease among Norwegian psychologists: The Alzheimer's disease knowledge scale. Aging \& Mental Health, 16(4), 521-528. Doi: 10.1080/13607863.2011.628973

Pallant, J. (2011). SPSS survival manual (4th ed.). Crows Nest, NSW: Allen \& Unwin. 
Rust, T. B., \& See, S. K. (2007). Knowledge about ageing and Alzheimer's disease: A comparison of professional caregivers and noncaregivers. Journal of Education Gerontology, 33, 349-364. Doi: 10.1080/03601270701199065

Rust, T. B., \& Kwong See, S. (2010). Beliefs about Ageing and Alzheimer's Disease in Three Domains. Canadian Journal on Ageing/La Revue Canadienne du Vieillissement, 29, 567-575. Doi: http://dx.doi.org/10.1017/S0714980810000590

Shum, D., O'Gorman, J., \& Myors, B. (2006). Psychological testing and assessment. Australia \& New Zealand: Oxford University Press.

Strobl, C., Kopf, J., \& Zeileis, A. (2010). A new method for detecting differential item functioning in the rasch model (Report No. 92). Retrieved from http://epub.ub.uni muenchen.de/11915/1/raschtree_techreport.pdf Tabachnick, B., \& Fidell, L. (2007). Using Mutlivariate Statistics (5th ed.). Boston, MA: Allyn \& Bacon.

Unwin, B. K., Unwin, C. G., Olsen, C., \& Wilson, C. (2008). A new look at an old quiz: Palmore's Facts on Aging Quiz turns 30. Journal of the American Geriatrics Society, 56(11), 2162-2164. Doi: 10.1111/j.1532-5415.2008.01998.x World Health Organisation. (2011). Global Health and Ageing. Retrieved 25 August 2012 from www.who.int/eu 
Government, Defence \& Legal

Engineering, Mining \& Construction

Retail, Sales, Marketing, IT, Hospitality \& Tourism

Self-Employed

Trades \& Services

Personal Contact with People with AD

No previous contact

Contact with a family member or friend/ acquaintance

Contact with both a family member and friend/acquaintance

$$
\begin{aligned}
& 14(5.6 \%) \\
& 13(5.2 \%) \\
& 20(8.0 \%) \\
& 6(2.4 \%) \\
& 6(2.4 \%)
\end{aligned}
$$

$56(22.3 \%)$

$114(45.4 \%)$

$76(30.3 \%)$

Note. ${ }^{\text {a }}$ There were missing data on demographic variables, hence percentages do not always add up to 100. TAFE $=$ Technical and Further Education, VET $=$ Vocational Education and Training. 
Table 2

Item Characteristics of the 25-item ADAPS

\begin{tabular}{|c|c|c|c|c|c|c|}
\hline $\begin{array}{l}\text { Fina } \\
\text { Item } \\
\text { no. }\end{array}$ & Item & $\begin{array}{l}\text { Subsc } \\
\text { ale of } \\
\text { ADA } \\
\text { PS }\end{array}$ & $\begin{array}{l}\text { Discrimi } \\
\text { nation } \\
\text { Index }\end{array}$ & $\begin{array}{l}\text { Diffic } \\
\text { ulty } \\
\text { Index }\end{array}$ & $\begin{array}{l}\text { Item- } \\
\text { total } \\
\text { correla } \\
\text { tion }\end{array}$ & $\begin{array}{l}\text { Alph } \\
\text { a if } \\
\text { item } \\
\text { dropp } \\
\text { ed }\end{array}$ \\
\hline 1 & $\begin{array}{l}\text { Difficulty entering a long sequence of } \\
\text { numbers over the phone to pay a bill }\end{array}$ & A & 30.8 & .70 & .02 & .69 \\
\hline 4 & $\begin{array}{l}\text { Indecisive when presented with a range of } \\
\text { options (e.g., shopping to buy a present for } \\
\text { someone) }\end{array}$ & A & 23.0 & .40 & .12 & .70 \\
\hline 6 & $\begin{array}{l}\text { Sometimes has difficulty finding a } \\
\text { particular word in conversation i.e. 'feels } \\
\text { as though it is on the tip of the tongue' }\end{array}$ & A & 46.1 & .40 & .24 & .69 \\
\hline 9 & $\begin{array}{l}\text { Difficulty remembering to perform an } \\
\text { errand that is not part of one's normal } \\
\text { routine }\end{array}$ & A & 23.1 & .34 & .13 & .70 \\
\hline 11 & Takes longer to solve problems effectively & A & 23.1 & .62 & .21 & .69 \\
\hline 16 & $\begin{array}{l}\text { Sometimes unsure if they completed } \\
\text { actions after leaving home (e.g., if doors } \\
\text { were locked or if the oven was switched } \\
\text { off) }\end{array}$ & A & 53.8 & .50 & .22 & .69 \\
\hline 21 & $\begin{array}{l}\text { Difficulty remembering when or where } \\
\text { they heard something }\end{array}$ & A & 30.7 & .44 & .10 & .70 \\
\hline 2 & $\begin{array}{l}\text { Difficulty shifting the focus of attention } \\
\text { from one task to the next }\end{array}$ & B & 61.5 & .54 & .52 & .66 \\
\hline 3 & $\begin{array}{l}\text { Loses track of the month or the season } \\
\text { (e.g. thinking its Summer when its late } \\
\text { Autumn) }\end{array}$ & B & 23.1 & .84 & .15 & .69 \\
\hline 5 & $\begin{array}{l}\text { Difficulty learning new information that is } \\
\text { important for their health (e.g., how to } \\
\text { change a dressing to prevent infection) }\end{array}$ & B & 23.1 & .68 & .10 & .70 \\
\hline 7 & $\begin{array}{l}\text { Difficulty spontaneously developing a } \\
\text { strategy to remember something (e.g., to } \\
\text { take medication each morning) }\end{array}$ & B & 30.8 & .74 & .16 & .69 \\
\hline
\end{tabular}


8 Difficulty completing tasks that were previously undertaken with ease (e.g., completing a government form)

$\begin{array}{lllll}\text { В } & 7.7 & .52 & .18 & .69\end{array}$

10 Difficulty managing a monthly budget, balancing figures or maintaining a cheque book or credit card

$\begin{array}{lllll}\text { B } & 30.7 & .38 & .18 & .69\end{array}$

12 Able to recall events from long ago more accurately than events that occurred recently (e.g., remembering changes in government 20 years ago compared to present times)

Table 2 (continued).

Final

Item

no. Item

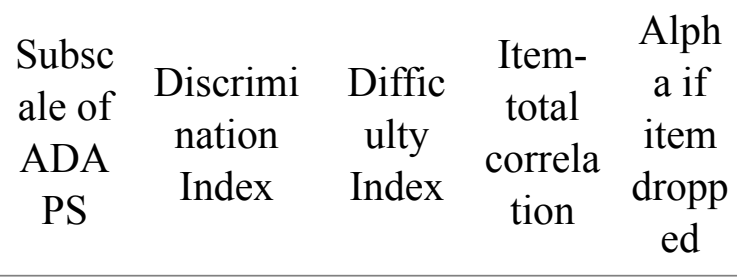

13 May forget that they have had visitors during the day when discussing the day's

$\begin{array}{llll}\text { B } & 23.1 & .92 & .29\end{array}$

$.29 \quad .69$
events

14 Difficulty developing a list (e.g., shopping list) because they forget items between checking what they need and

$\begin{array}{lllll}\text { B } & 38.4 & .68 & .31 & .68\end{array}$
writing these down

15 May not respond to changes in the environment (e.g., putting a jumper on when it gets cold)

$\begin{array}{lllll}\text { B } & 30.7 & .68 & .28 & .68\end{array}$

17 Difficulty operating familiar household items, such as an iron, microwave,

$\begin{array}{llll}\text { B } & 30.8 & .72 & .29\end{array}$
.68 telephone

18 Refers to objects as "the thing" rather than using its proper name (e.g., can you pass me the thing that adds up numbers)

$\begin{array}{lllll}\text { B } & 38.4 & .48 & .28 & .68\end{array}$

19 Trouble recognising a picture of a famous landmark e.g. Sydney Opera House or $\begin{array}{lllll}\text { B } & 15.4 & .74 & .17 & .69\end{array}$ Eiffel Tower or The Great Wall of China

20 Needs assistance to complete some multistep activities in daily living (e.g., B $\quad 76.9$ $.46 \quad .54$ .66 shopping, preparing meals) 
22 Difficulty recalling the gist of an interesting story told or a movie watched earlier in the day

$\begin{array}{lllll}\text { В } & 38.4 & .66 & .27 & .69\end{array}$

23 Unaware of difficulties they have with driving that places them at risk

$\begin{array}{lllll}\text { B } & 53.8 & .40 & .40 & .67\end{array}$

24 Difficulty maintaining a concept of time (e.g., believe that their grandson or granddaughter at university is still in high B school)

25 Misplaces objects because they have put them in unusual places (e.g., keys in the bathroom cabinet)

$\begin{array}{lllll}\text { B } & 23.1 & .76 & .28 & .68\end{array}$

Note. ${ }^{\text {a }}$ Items of the final 25 -item version of the ADAPS; ${ }^{\mathrm{b}}$ Subscales on the ADAPS: A = Can be characteristics of normal ageing, $\mathrm{B}=\mathrm{Can}$ be characteristic of $\mathrm{AD}$, and $\mathrm{C}=\mathrm{Not}$ characteristic of normal ageing or AD. 
Table 3

Pearson Product Moment Correlations for Convergent Validity of the Total ADAPS and the ADAPS Subscales with the KMAQ and ADKS for the General Community Sample ( $n=196)$

\begin{tabular}{ccccc}
\hline & Normal Ageing & Alzheimer's Disease & Total & \\
& Subscale & Subscale & ADAPS & ADKS \\
\hline KMAQ & $.224^{* *}$ & .052 & $.154^{*}$ & $.424^{* * *}$ \\
ADKS & $.152^{*}$ & $.143^{*}$ & $.200^{* *}$ & - \\
\hline
\end{tabular}

${ }^{*} p<.05 \quad * * p<.01 \quad * * * p<.001 ;$ Key: ADAPS = Alzheimer's Disease and Ageing Perception Scale; ADKS = Alzheimer's Disease Knowledge Scale; KMAQ = Knowledge of Memory Ageing Questionnaire. 
Table 4

The Ten Most Prevalent Misconceptions of the Cognitive Effects of Ageing and Alzheimer's

Disease $(n=196)$

\begin{tabular}{|c|c|c|}
\hline Item & $\begin{array}{l}\text { Correct } \\
\text { Answer }\end{array}$ & $\begin{array}{c}\% \\
\text { Correct }\end{array}$ \\
\hline $\begin{array}{l}\text { Difficulty managing a monthly budget, balancing figures or } \\
\text { maintaining a cheque book or credit card }\end{array}$ & $\mathrm{AD}$ & 34.7 \\
\hline $\begin{array}{l}\text { Unaware of difficulties they have with driving that places } \\
\text { them at risk }\end{array}$ & $\mathrm{AD}$ & 41.8 \\
\hline $\begin{array}{l}\text { Difficulty completing tasks that were previously undertaken } \\
\text { with ease (e.g., completing a government form) }\end{array}$ & $\mathrm{AD}$ & 42.9 \\
\hline $\begin{array}{l}\text { Needs assistance to complete some multi-step activities in } \\
\text { daily living (e.g., shopping, preparing meals) }\end{array}$ & $\mathrm{AD}$ & 43.9 \\
\hline $\begin{array}{l}\text { Refers to objects as "the thing" rather than using its proper } \\
\text { name (e.g., can you please pass me the thing that adds } \\
\text { up numbers) }\end{array}$ & $\mathrm{AD}$ & 45.9 \\
\hline $\begin{array}{l}\text { Indecisive when presented with a range of options (e.g., } \\
\text { shopping to buy a present for someone) }\end{array}$ & NA & 46.4 \\
\hline $\begin{array}{l}\text { Difficulty shifting the focus of attention from one task to } \\
\text { the next }\end{array}$ & $\mathrm{AD}$ & 48.0 \\
\hline $\begin{array}{l}\text { Difficulty remembering to perform an errand that is not part } \\
\text { of one's normal routine }\end{array}$ & NA & 51.0 \\
\hline $\begin{array}{l}\text { Misplaces objects because they have put them in unusual } \\
\text { places (e.g., keys in the bathroom cabinet) }\end{array}$ & $\mathrm{AD}$ & 51.0 \\
\hline $\begin{array}{l}\text { Difficulty recalling the gist of an interesting story told or a } \\
\text { movie watched earlier in the day }\end{array}$ & $\mathrm{AD}$ & 54.1 \\
\hline
\end{tabular}

${ }^{a}$ Represents the percentage of participants who got the answer correct. NA = normal ageing, $\mathrm{AD}=$ Alzheimer's disease 